Historic, Archive Document

Do not assume content reflects current scientific knowledge, policies, or practices. 



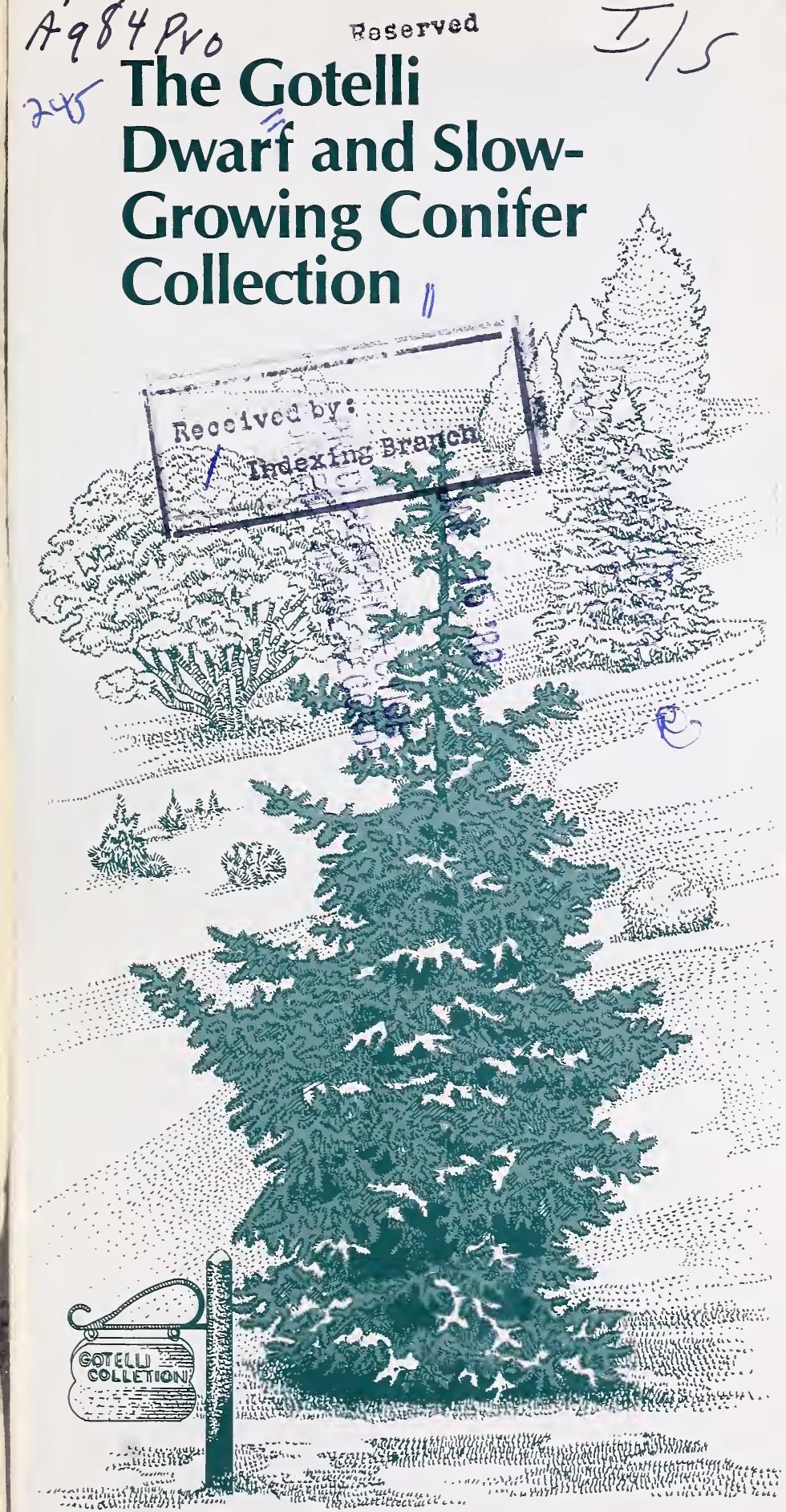




\section{The Gotelli Dwarf and Slow-Growing Conifer Collection}

The Gotelli Collection of Dwarf and SlowGrowing Conifers is considered by many to be one of the finest collections of dwarf conifers in the world.

The collection was donated to the U.S. National Arboretum by William T. Gotelli in 1962. Mr. Gotelli was a building contractor who collected most of the conifers as a hobby over a 15 -year period. $\mathrm{He}$ obtained the plants from nurseries, estates, and botanical gardens in the United States, Europe, Canada, Japan, Australia, and New Zealand.

This incomparable collection of about 1,500 specimens represents 30 genera in numerous varieties of fir, cedar, false cypress, juniper, spruce, pine, yew, arborvitae, hemlock, and other miscellaneous genera.

The plants are set in attractive plantings, mulched with crushed blue stone, and are separated by grass areas and walks which permit close inspection of individual plants.

The collection was laid out according to plans prepared by John Jennings, the landscape architect who assisted Mr. Gotelli in assembling and developing his original plantings at his home in East Orange, New Jersey.

The collection occupies an attractive hillside site of about 5 acres in the northeastern section of the Arboretum. With the first distant view, upon approaching the hillside, one cannot help but become fascinated by the assortment of interesting shapes and color forms which occur in the Gotelli Collection.

These unusual dwarf conifers well illustrate the infinite variation of form and color found in nature, and allow the visitor the opportunity to appreciate how subtle variations in plants have been selected and perpetuated by horticulturists. 
Simulated rock outcroppings and supplementary plantings of ornamental grasses, perennials, and bulbs among the conifers provide contrast and depth to the collection. Display labels identifying each of the dwarf conifer specimens increase the interest and educational value of the collection.

Diligent observations of the Gotelli Collection over the past few years have provided much needed information as to which additional cultivars are worth introducing to the nursery trade. The collection also serves to focus attention on research essential to resolving some of the complex taxonomic and nomenclatural problems that have plagued dwarf conifer enthusiasts for many years.

Mr. Gotelli desired that propagations from his collection be made available to other arboreta and botanic gardens where they might find their way to commercial nurseries and the public. Several cultivars have already been distributed through the U.S. National Arboretum's cooperative programs.

The term "dwarf conifer" applies to a conifer which never attains the stature that is normal for the original plant from which it derives, whether it be a species, variety, or cultivar. ${ }^{1}$

"Dwarfing" may be due to a chance seedling variation, a virus disease, a bud mutation, an insect irritation, or an environmental variation due to the effects of climatic or geographic situations. In each case, the altered growth rate results in the dwarfing of the plant. Such conifers are naturally slow growing and are true dwarfs in contrast to artifically produced miniatures, such as the well-known Japanese bonsai, which require regular care and pruning to maintain their dwarf stature.

In some instances, the needles are dwarf in addition to the growth of the stem, adding yet another dimension to the charm and character of dwarf conifers. Dwarf conifers often grow not more than a quarter of an inch per year.

The slow-growth rate of dwarf conifers offers a distinct and practical advantage in that very little, if any, pruning is required. However, the plants must be observed for reverted branches (branches that return to their natural habit) where vigorous growth

${ }^{1}$ Species refers to a group of plants (or animals) that have in. common one or more distinctive characteristics that are reproduced in their offspring. 


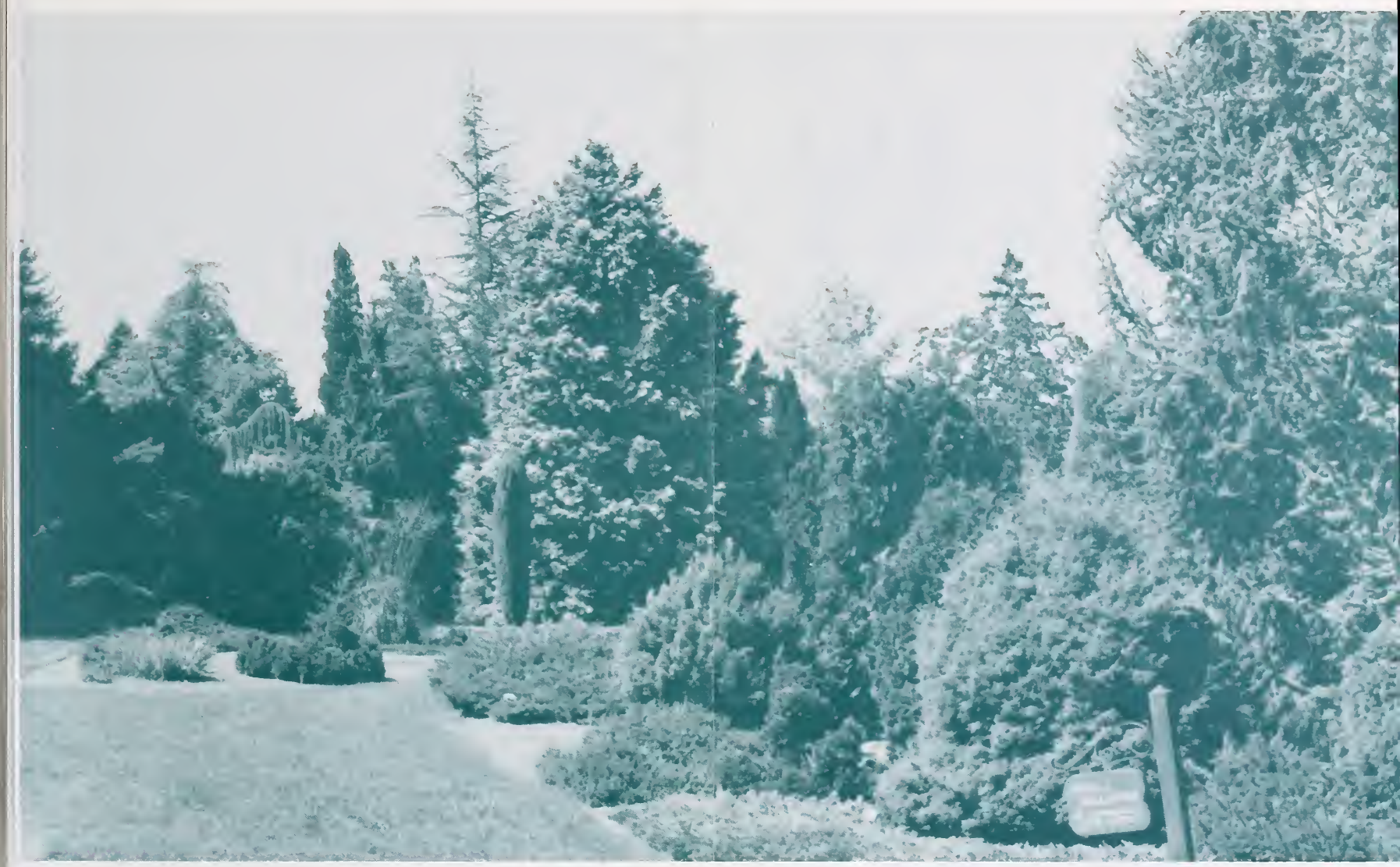

could eventually eliminate the desired form. Such branches must be removed from the plants whenever they appear.

\section{Culture}

Dwarf conifers generally prefer a sunny but somewhat protected location and a slightly acid soil that is well drained. The use of highly fertile soil or more than a rare application of fertilizer should be avoided, as both tend to stimulate rank growth. Plants with good color and those with satisfactory annual growth generally do not need fertilizers. A surface application of organic matter, such as shredded bark or leaf mold, will usually provide an adequate source of nutrients.

\section{Planting}

The best time to plant dwarf conifers is during cool weather and when the plants are in a semidormant condition (September to November). Dwarf conifers, like most of their larger species, require a rootball when transplanted.

\section{Landscape Uses}

Dwarf conifers may be used effectively as features in foundation plantings, groundcovers, or as specimen plants. In rock gardens they provide an interesting contrast to alpine plants, bulbs, perennials, and an occasional flowering tree or shrub.

The trend toward smaller gardens in the last few decades has generated a great interest in dwarf plants, especially conifers. Their varied and picturesque shapes, texture, numerous color variations, length of life, ease of maintenance, and sheer versatility offer many unusual opportunities for nurseries, amateur gardeners, and landscape architects alike.

October 1987

This Program Aid supersedes "The Gotelli Dwarf Conifer Collection," Program Aid No. 1159 


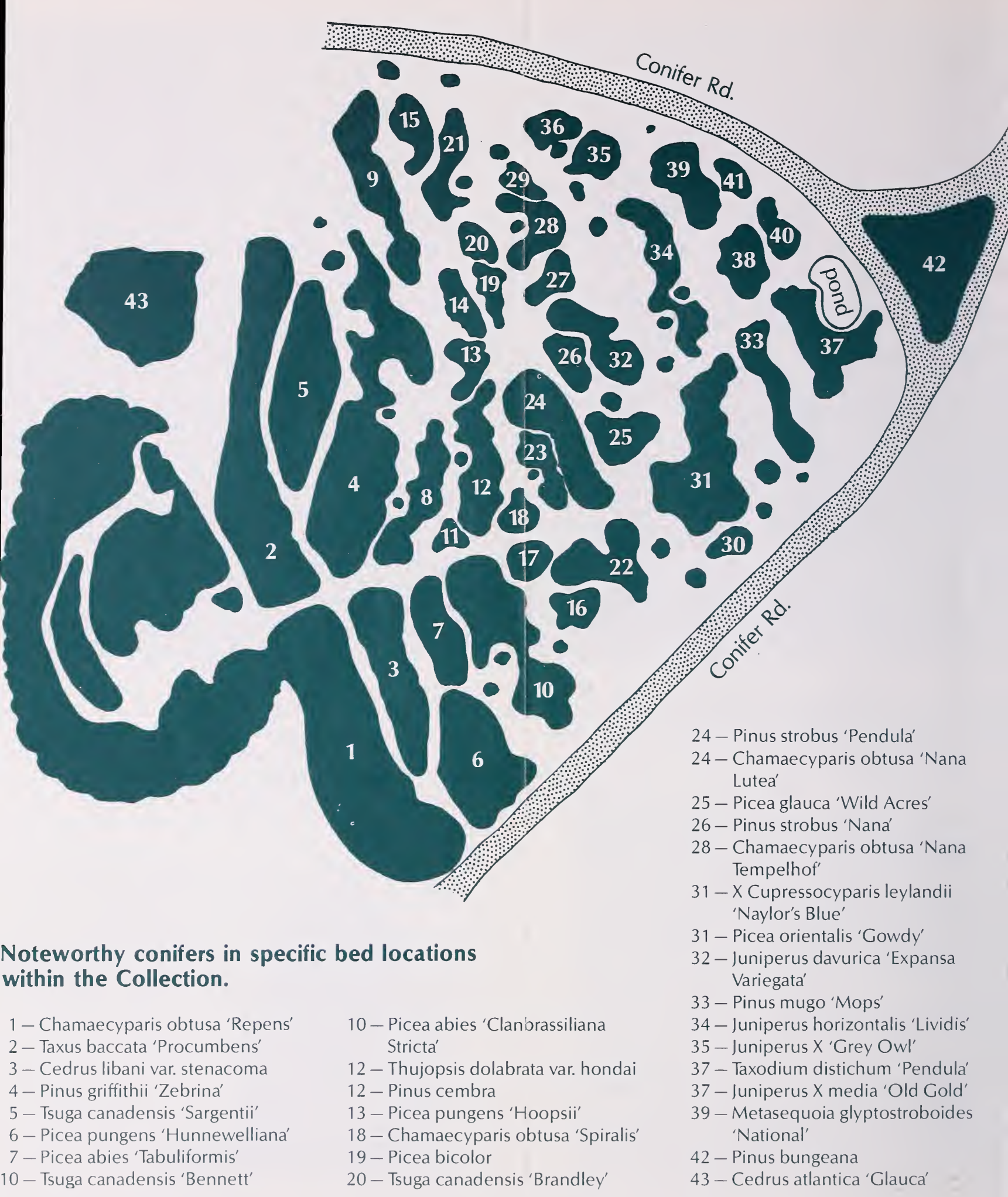

